\title{
Sústalinable

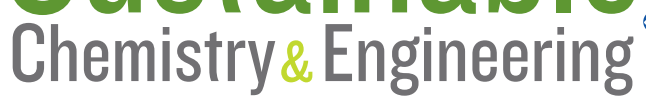 \\ Biochar Surface Oxygenation by Ozonization for Super High Cation Exchange Capacity
}

Gyanendra Kharel, ${ }^{\dagger, \$}$ Oumar Sacko, ${ }^{\dagger, \$}$ Xu Feng, ${ }^{\ddagger}$ John R. Morris, ${ }^{\ddagger \oplus}$ Claire L. Phillips, ${ }^{\S}$ Kristin Trippe, ${ }^{\S}$ Sandeep Kumar, ${ }^{\| \bullet}$ and James W. Lee ${ }^{* \dagger}{ }^{\dagger}$

${ }^{\dagger}$ Department of Chemistry and Biochemistry, Old Dominion University, Norfolk, Virginia 23529, United States

${ }^{\ddagger}$ Department of Chemistry, Virginia Tech, Blacksburg, Virginia 24061, United States

${ }^{\S}$ USDA ARS, Forage Seed and Cereal Research Unit, 3450 SW Campus Way, Corvallis, Oregon 97331, United States

"Department of Civil \& Environmental Engineering, Old Dominion University, Norfolk, Virginia 23529, United States

\section{Supporting Information}

ABSTRACT: Biochar cation exchange capacity (CEC) is a key property central to better retention of soil nutrients and reduction of fertilizer runoff. This paper reports a breakthrough process to improve biochar CEC value by a factor of nearly 10 through biochar surface oxygenation by ozonization. The CEC value of the untreated biochar was measured to be anywhere between 14 and $17 \mathrm{cmol} / \mathrm{kg}$. A $90 \mathrm{~min}$ dry ozonization treatment resulted in an increased biochar CEC value of $109-152 \mathrm{cmol} / \mathrm{kg}$. Simultaneously, the biochar ozonization process resulted in a reduction of biochar $\mathrm{pH}$ from 9.82 to as low as 3.07 , indicating the formation of oxygen-functional groups including carboxylic acids on biochar surfaces. Using the technique of X-ray photoelectron spectroscopy (XPS), the formation of oxygen-functional groups including

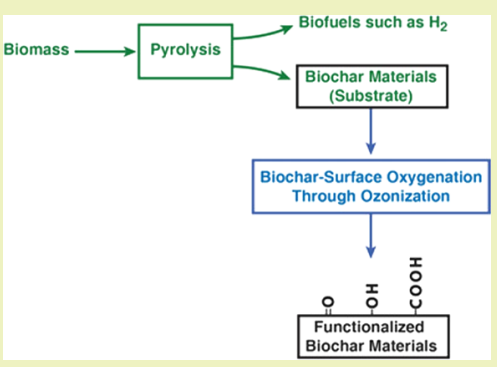
carboxylic acids on biochar surfaces have been observed at a nanometer molecular scale following the ozonization treatment. The molar $\mathrm{O} / \mathrm{C}$ ratio $(0.31: 1)$ on ozonized biochar surface as analyzed by XPS was indeed significantly higher than that $(0.16: 1)$ of the control biochar surface. The molar O/C ratio from the elemental analysis data also showed an increase from the nonozonized sample $(0.077: 1)$ to the dry-ozonized sample (0.193:1). Fourier-transform infrared (FTIR) spectroscopy analysis also showed an increase in the content of oxygen-functional groups in the form of carbonyl groups on biochar surfaces upon ozonization, which can also produce certain amount of oxygenated biochar molecular fragments that may be solubilized by liquid water, potentially leading to greater effects upon application of biochar in soil.

KEYWORDS: Biochar surface oxygenation, Cation exchange capacity, Biochar ozonization, X-ray photoelectron spectroscopy, Oxygen functional groups on biochar surface

\section{INTRODUCTION}

Biochar, a carbon-rich soil amendment, has been used for several centuries to improve soil fertility and increase yield. While recent interest in biochar has produced an abundance of scientific knowledge, variability in the physiochemical properties of biochar and an inability to predict biochar-soil interactions and agronomic outcomes have stifled the implementation of biochar-related practices. While some studies show improvements in crop production and soil fertility following biochar amendment, meta-analyses also demonstrate no improvements or declines in crop production in a large fraction of studies. ${ }^{1-3}$

The enhanced fertility of soils historically amended with charcoal, such as Amazonian Terra Preta soils, can be partially attributed to improved cation exchange capacity (CEC).,5 CEC is a key indicator of soil fertility, buffering capacity, and water holding capacity. ${ }^{6-8}$ However, many contemporary biochars have a low CEC (mostly below a typical soil CEC value of $15 \mathrm{cmol} / \mathrm{kg}$ ) and weathering studies have demonstrated that the natural surface oxygenation of biochar develops at decadal time scales. ${ }^{9-11}$ Thus, the variability of crop response to biochar-amended soils may be attributed to their low CEC. ${ }^{12,13,7,14-16}$ Therefore, biochars with greater CECs are critically needed to achieve the mission of biochar as a soil amendment and carbon sequestration agent. ${ }^{17-20}$

While a high $\mathrm{O} / \mathrm{C}$ ratio may be desirable for high $\mathrm{CEC},{ }^{21}$ it must also be understood that the higher the $\mathrm{O} / \mathrm{C}$ ratio, the shorter the overall half-life of biochar when placed in soils. Biochars with $\mathrm{O} / \mathrm{C}$ ratios $<0.2$ have half-lives more than 1000 years in natural soil environments. ${ }^{22}$ The expected half-lives drop precipitously to $<100$ years for an $\mathrm{O} / \mathrm{C}$ ratio of $\geq 0.6$. An ideally designed biochar for use as both a soil amendment and carbon sequestering agent would need to enhance the $\mathrm{O} / \mathrm{C}$ ratio only on the surface of biochar, ${ }^{23}$ giving a higher CEC, while still maintaining the poly aromaticity (preferably lower $\mathrm{O} / \mathrm{C}$ ratio) of the biochar core to ensure long-term stability.

This article reports a technological solution that dramatically increases the CEC of biochars through surface oxygenation.

Received: June 21, 2019

Revised: August 18, 2019

Published: September 4, 2019 
The underlying concept is that an innovative application of postproduction biochar ozonization (Figure 1) can cost-

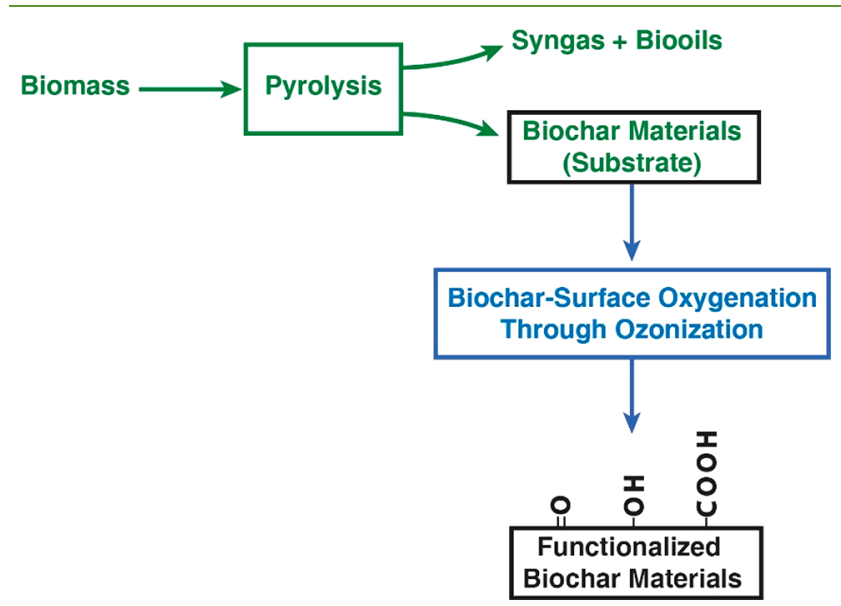

Figure 1. Schematic for postproduction biochar ozonization to create oxygen containing functional groups on biochar surfaces.

effectively create oxygen-containing functional groups on biochar surfaces that will substantially increase its CEC and improve its performance in agronomic and remediation applications.

According to our preliminary understanding, ${ }^{23,24}$ the most significant reactions of $\mathrm{O}_{3}$ with organic matter are likely based on the cleavage of the carbon double bond, which acts as a nucleophile having excess electrons. The injected $\mathrm{O}_{3}$ stream may lead to the formation of carbonyl and carboxyl groups on biochar surfaces by reacting with carbon-carbon $(\mathrm{C}=\mathrm{C})$ double bonds at ambient pressure and temperature.

$$
\text { Biochar }-\mathrm{CH}=\mathrm{CH}-\text { Biochar }+\mathrm{O}_{3} \rightarrow \text { Biochar }-\mathrm{COH}+\text { Biochar }-\mathrm{COOH}
$$

In this case, the ozonized biochar will become more hydrophilic since both carbonyl and carboxyl groups can attract water molecules. Because the carboxyl groups readily deprotonate in water and result in more negative charge on biochar surfaces, it will also increase the CEC.

$$
\text { Biochar- } \mathrm{COOH} \rightarrow \text { Biochar- } \mathrm{COO}^{-}+\mathrm{H}^{+}
$$

In a previous study, ${ }^{23}$ we tested this biochar ozonization process and observed an increase in the CEC value of the biochar by a factor of nearly 2 . In the present study, using a biochar material with high BET surface area, the use of ozonization resulted in an increase in biochar CEC to over 100 $\mathrm{cmol} / \mathrm{kg}$, which may represent a significant breakthrough in biochar science and technology.

\section{MATERIALS AND METHODS}

Characterization of Biochar. The Rogue Biochar used during the experiment was obtained from Oregon Biochar Solutions. According to the company, the biochar was made from softwood tree materials such as Douglas fir, sugar pine, etc. The biochar was characterized by the International Biochar Initiative (IBI, Lab ID number 7020309-01). The characteristics of the Rogue biochar are represented in Table $\mathrm{S} 1$ of the Supporting Information.

Dry Ozone Treatment. The Rogue biochar obtained from Oregon Biochar Solutions was oven-dried overnight at $105{ }^{\circ} \mathrm{C}$ in an electric oven. The biochar was then ground, sieved using a $106 \mu \mathrm{m}$ sieve, washed with ultrapure water $(100 \mathrm{~mL}$ per gram $)$, and placed back in the oven at $105{ }^{\circ} \mathrm{C}$ overnight for drying. This biochar is referred to as RBC UN in the paper. A $1.5 \mathrm{~g}$ portion of the oven-dried biochar was weighed and placed in an ozone treatment vessel. The ozone generator (Welsbach T-series) was set to optimum condition for the generation of ozone as described next. Briefly, the oxygen pressure was set to $8 \mathrm{psi}$, and the flow of oxygen/ozone was set to 3 $\mathrm{L} / \mathrm{min}$. The ozone gas stream was passed into the sample containing reactor vessel for a duration of $90 \mathrm{~min}$. During the treatment, the sample reactor vessel was shaken in regular intervals of $15 \mathrm{~min}$ in order to treat every particle of biochar with ozone. After $90 \mathrm{~min}$, the biochar was washed thoroughly in two steps with ultrapure water. The first rinse of $25.0 \mathrm{~mL}$ and the second rinse of $300 \mathrm{~mL}$ were both collected in vessels for subsequent dissolved organic carbon (DOC) determination. The washed biochar was then placed in the oven at $105^{\circ} \mathrm{C}$ for drying. This ozonized biochar is called as RBC $90 \mathrm{D}$ in the paper. Proportional amounts of ultrapure water were also used to rinse $3 \mathrm{~g}$ of $\mathrm{RBC} \mathrm{UN}$ biochar, and filtrates were collected for subsequent DOC determination.

$\mathrm{pH}$ Determination. The biochar $\mathrm{pH}$ was recorded with a Beckman Coulter Phi $570 \mathrm{pH}$ meter connected to a Thermo Scientific Orion $\mathrm{pH}$ probe. To determine the biochar $\mathrm{pH}$, three replicates of $1.0 \mathrm{~g}$ each of $\mathrm{RBC} \mathrm{UN}$ and $\mathrm{RBC} 90 \mathrm{D}$ biochar were taken and placed into $50 \mathrm{~mL}$ centrifuge tubes with $10 \mathrm{~mL}$ of ultrapure water added to each tube. For the RBC 90D biochar, $\mathrm{pH}$ was determined both before and after the rinsing procedure described above, in order to determine the impact of the DOC component. The tubes with the mixture were then placed on a shaker Innova 2300 platform shaker (New Brunswick Scientific, Eppendorf AG, Germany) and the shaker was set at $120 \mathrm{rpm}$ for $1 \mathrm{~h}$. After shaking, the $\mathrm{pH}$ of the slurry of each sample was recorded.

CEC Measurement Using the AOAC Method (at the ODU Laboratory). To determine the biochar CEC, a similar approach with a modified protocol from AOAC method 973.09 as reported by Rippy et al. (2007) was used. ${ }^{25}$ Briefly, six replicates of $0.5 \mathrm{~g}$ each of RBC UN and RBC 90D biochars were taken and each of the $0.5 \mathrm{~g}$ samples was placed into a $125 \mathrm{~mL}$ Erlenmeyer flask with $50 \mathrm{~mL}$ of 0.5 $\mathrm{M}$ hydrochloric acid $(\mathrm{HCl})$ added to each flask. The flasks with the mixture were then placed on the shaker set at $120 \mathrm{rpm}$ and shaken for $2 \mathrm{~h}$. The mixture was then filtered and washed through a Whatman GF/F $70 \mathrm{~mm}$ glass microfiber filter with $100 \mathrm{~mL}$ portions of Millipore water until no precipitation of chloride as silver chloride $(\mathrm{AgCl})$ was seen upon the addition of silver nitrate $\left(\mathrm{AgNO}_{3}\right)$ in the filtrate. The biochar residue was then transferred into a clean $125 \mathrm{~mL}$ Erlenmeyer flask along with the filter paper, and $50 \mathrm{~mL}$ of $0.5 \mathrm{M}$ barium acetate $\left(\mathrm{Ba}(\mathrm{OAc})_{2}\right)$ was added to each flask. The flasks with the mixture were again placed in the shaker set at $120 \mathrm{rpm}$ for $2 \mathrm{~h}$. The mixture was then filtered and washed with $300 \mathrm{~mL}$ of Millipore water. The residue was discarded, whereas the filtrate was then titrated with $0.025 \mathrm{M}$ sodium hydroxide $(\mathrm{NaOH})$ solution until the end point $(\mathrm{pH}=8.2)$ was reached. The CEC was then calculated using the following equation

$$
\frac{\mathrm{cmol}}{\mathrm{Kg} \text { biochar }}=\frac{\mathrm{ml} \mathrm{NaOH} \times \text { molarity } \mathrm{NaOH} \times 100}{\text { gram sample }}
$$

Independent CEC Measurement Using Modified Ammonium Acetate $\left(\mathrm{NH}_{4} \mathrm{OAc}\right)$ Method (at the USDA/ARS Laboratory). Samples of the biochars (RBC UN and RBC 90D) were sent to the USDA-ARS Laboratory for independent CEC measurements using an ammonium acetate $\left(\mathrm{NH}_{4} \mathrm{OAc}\right)$ method (Graber et al., 2017) with modifications suggested by Munera-Echeverri et al. (2018). ${ }^{26}$ Because CEC is $\mathrm{pH}$-dependent, biochar samples were pretreated by adjusting the $\mathrm{pH}$ to 7 . Briefly, $1 \mathrm{~g}$ of dried biochar was mixed with 20 $\mathrm{mL}$ of deionized water and shaken horizontally for $4 \mathrm{~h}$ at $200 \mathrm{rpm}$ to ensure complete wetting. $\mathrm{HCl}(1.5 \mathrm{M})($ or $\mathrm{NaOH})$ was used to adjust the $\mathrm{pH}$ of the slurry to 7 . The $\mathrm{pH}$ was monitored periodically over 48 $h$ to ensure it had stabilized, and the water was removed by filtration through $2 \mu \mathrm{m}$ filter paper (Whatman Nucleopore Track-Etch membrane). As a modification of Munera-Echeverri et al. (2018), extraction steps were performed using a filtration apparatus instead of a centrifuge, because the ozone-treated biochar did not form a translucent supernatant. A fresh $2 \mu \mathrm{m}$ filter and Whatman glass funnel were prepared on a $250 \mathrm{~mL}$ Erlenmeyer flask. The $\mathrm{pH}$-adjusted 
biochar sample and $20 \mathrm{~mL}$ of $1 \mathrm{M} \mathrm{NH}_{4} \mathrm{OAc}$ were added to the funnel, swirled, and let to stand on the funnel for $2 \mathrm{~h}$ before applying vacuum to remove the $\mathrm{NH}_{4} \mathrm{OAc}$. Repeated additions of $20 \mathrm{~mL} \mathrm{NH}_{4} \mathrm{OAc}$ were performed for a total of 4 times. For the fourth addition, the $\mathrm{NH}_{4} \mathrm{OAc}$ and biochar mixture was left to stand overnight before vacuuming. Next, repeated additions of $20 \mathrm{~mL}$ of ethanol (EtOH 100\%) were used to remove the noncomplexed $\mathrm{NH}_{4}$. EtOH was added to the funnel, swirled to mix with the biochar, and allowed to stand for $2 \mathrm{~h}$ before vacuuming. The EtOH wash was performed 4 times. The complexed $\mathrm{NH}_{4}$ was then displaced with potassium chloride $(\mathrm{KCl})$; $20 \mathrm{~mL}$ of $2 \mathrm{M} \mathrm{KCl}$ was added to the biochar sample, swirled and allowed to stand for $2 \mathrm{~h}$, and then vacuum was applied to collect the filtrate in an Erlenmeyer flask. A total of four extractions were done, producing $80 \mathrm{~mL}$ of extracted volume. Lastly, the ammonium was measured colorimetrically using a microplate reader (Ringuet et al., 2011), and CEC was calculated as follows

$$
\mathrm{CEC}\left(\mathrm{cmol}_{\mathrm{c}} \mathrm{kg}^{-1}\right)=\frac{\mathrm{NH}_{4}^{+} \text {conc }\left(\mathrm{mgL}^{-1}\right) \times V(\mathrm{~mL}) \times 100}{\text { molecular mass of } \mathrm{NH}_{4}^{+} \times W(\mathrm{~g})}
$$

Triplicate samples of each biochar type were measured.

Surface Area Measurement with BET. The surface area was measured for the biochar samples before and after ozonization by using the Brunauer-Emmett-Teller (BET) nova 2000e series instrument. The biochar was weighed (about $0.1-0.3 \mathrm{~g}$ ) and inserted into the sample cell. The biochar was then vacuum-degassed for $4 \mathrm{~h}$ at $150{ }^{\circ} \mathrm{C}$. Helium at $10 \mathrm{psi}$ was used for the backfill. The mass of the degassed biochar was then measured. For the analysis portion, the biochar samples were bathed in liquid nitrogen at $77 \mathrm{~K}$, and the nitrogen pressure was set to 10 psi. The multipoint BET technique was then used to obtain the surface area of the biochar samples. The surface area was measured for both the ground and sieved biochar samples (RBC UN and RBC 90D) as well as the unground biochar samples (RBC UN and RBC 90D) before and after ozonization. For a comparative analysis, the surface area was also measured for a nonozonized ground and sieved biochar from slow pyrolysis (30 min) of pine wood biomass at $400{ }^{\circ} \mathrm{C}(\mathrm{P} 400)$. The same procedure as done for the RBC UN and RBC 90D was used for measuring the surface area of the P400 except that the backfill was done with the adsorbate (here nitrogen) instead of helium. The reason for the change in the backfill gas was as follows: due to the P400 being microporous, the method using helium as a backfill resulted in the inability of the nitrogen gas to adsorb and desorb on the surface, thus resulting in no measurable BET surface area. This may be due to possible entrapment of helium in the micropores of the biochar. To circumvent that limitation, nitrogen gas was used as backfill instead of helium. In order to verify the validity of this method, the ground $R B C \mathrm{UN}$ and $\mathrm{RBC}$ 90D (before and after ozonization) had their surface areas remeasured with nitrogen as the backfill gas.

Fourier-Transform Infrared (FTIR) Spectroscopy. Biochar FTIR spectroscopy was analyzed on a Nicolet 6700 FT-IR spectrometer from Thermo Scientific using a pellet. A $1 \mathrm{mg}$ portion of finely ground samples of RBC UN and RBC 90D biochar were mixed with $300 \mathrm{mg}$ of predried and ground FT-IR grade $\mathrm{KBr}$. The FTIR spectra were recorded over the range of $400-4000 \mathrm{~cm}^{-1}$ with the resolution of 4 $\mathrm{cm}^{-1}$ and 64 scans per sample.

Dissolved Organic Carbon Measurement. The dissolved organic carbon (DOC) concentrations of the filtrates collected from the wash of the dry-ozonized biochar (RBC 90D) and the nonozonized control biochar (RBC UN) were measured using a TOC-Analyzer (Shimadzu TOC-V CPH); the filtrate collection method was described in the section with dry ozone treatment above. Briefly, the DOC concentration was measured from the first wash and the second wash collected from each biochar. The total amount of DOC in $\mathrm{mg}$, extracted from the first and second wash, was combined and divided by the mass of biochar sample in order to get the mg of DOC per gram of biochar. Prior to the measurement, in order to exclude the nondissolved organic materials, the solutions were filtered through a hydrophobic polytetrafluoroethylene (PTFE) $0.2 \mu \mathrm{m}$ filter
(Millex-FG SLFG025LS). The samples were then diluted at two different concentrations, and the DOC was measured.

X-ray Photoelectron Spectroscopy. Samples of untreated control biochar (RBC UN) and the dry-ozonized biochar (RBC 90D) were sent to the Department of Chemistry in Virginia Tech (Blacksburg, VA 24061) for X-ray Photoelectron Spectroscopy (XPS) analysis. The experimental method is as follows. XPS characterization was performed on a PHI VersaProbe III scanning XPS microscope using monochromatic $\mathrm{Al} \mathrm{K} \alpha \mathrm{X}$-ray source $(1486.6 \mathrm{eV})$. Spectra were acquired with $100 \mu \mathrm{m} / 100 \mathrm{~W} / 20 \mathrm{kV}$ X-ray and dual-beam charge neutralization over a $1400 \mu \mathrm{m} \times 100 \mu \mathrm{m}$ area. All binding energies were referenced to $\mathrm{C}-\mathrm{C}$ at $284.8 \mathrm{eV}$.

Survey: $280 \mathrm{eV}$ Pass Energy, $1.0 \mathrm{eV} / \mathrm{step}, 50 \mathrm{~ms} / \mathrm{step}, 10$ sweeps; C 1s: $26 \mathrm{eV}$ Pass Energy, $0.1 \mathrm{eV} / \mathrm{step}, 50 \mathrm{~ms} / \mathrm{step}, 10$ sweeps; O 1s: 26 eV Pass Energy, $0.1 \mathrm{eV} / \mathrm{step}, 50 \mathrm{~ms} / \mathrm{step}, 30-40$ sweeps; chemical states of elements were assigned based on the PHI and NIST XPS databases.

Elemental Analysis (Oxygen and Carbon). The ground and sieved nonozonized control biochar (RBC UN) and the dry-ozonized biochar (RBC 90D) samples were sent to the Kumar lab at ODU for Elemental Analysis. It was performed using a FLASH 2000 Organic Elemental Analyzer to determine the oxygen and carbon contents of the biochar samples. In the elemental analysis, the measured mass percentages of oxygen and carbon were converted to molar percentages by dividing the weight percent of each element with its molar mass. The molar $\mathrm{O} / \mathrm{C}$ ratio was determined by dividing the molar percentages of $\mathrm{O}$ with that of $\mathrm{C}$.

Scanning Electron Microscopy/Energy Dispersive X-ray Spectroscopy. Samples of untreated control biochar (RBC UN) and the dry-ozonized biochar (RBC 90D) were sent to the Nanoscale Characterization and Fabrication Laboratory in Virginia Tech (Blacksburg, VA 24061) for SEM/EDS analysis using an FEI Quanta 600 FEG environmental scanning electron microscope and a Bruker QUANTAX 400 energy dispersive X-ray spectrometer.

\section{RESULTS AND DISCUSSION}

Effect of Ozonization on Biochar $\mathrm{pH}$. The biochar $\mathrm{pH}$ was drastically reduced as a result of the ozone treatment. The untreated control sample of biochar had a basic $\mathrm{pH}$ value of $9.82 \pm 0.03$. After $90 \mathrm{~min}$ of dry-ozone treatment, the biochar $\mathrm{pH}$ dropped down to $3.07 \pm 0.03$ (Table 1). The decrease in biochar $\mathrm{pH}$ is consistent with the understanding that biochar ozonization can create carboxylic acid groups on biochar surfaces, as demonstrated by FT-IR and XPS analyses (see text below). The carboxylic acid groups on biochar surfaces can deprotonate, displaying low $\mathrm{pH}$ characteristics as shown in eq 2. To make sure that the acidic $\mathrm{pH}$ was not due to any water-

Table 1. pH, CEC, and BET Surface Area of the Ground Biochar before and after Ozonization ${ }^{a}$

\begin{tabular}{|c|c|c|}
\hline Parameters & $\begin{array}{l}\text { Nonozonized Biochar } \\
\text { (RBC UN) (means } \pm \\
\text { SD) }\end{array}$ & $\begin{array}{c}\text { Dry-ozonized Biochar } \\
\text { (RBC 90D) (means } \pm \\
\text { SD) }\end{array}$ \\
\hline $\mathrm{pH}$ & $9.82 \pm 0.03$ & $3.07 \pm 0.03$ \\
\hline $\begin{array}{l}\mathrm{CEC}(\mathrm{cmol} / \mathrm{kg}) \\
\text { measured by } \\
\mathrm{Ba}(\mathrm{OAc})_{2} \text { method }\end{array}$ & $17.02 \pm 0.63$ & $152.08 \pm 4.06$ \\
\hline $\begin{array}{l}\mathrm{CEC}(\mathrm{cmol} / \mathrm{kg}) \\
\text { measured by } \mathrm{NH}_{4^{-}} \\
\text {OAc method }\end{array}$ & $14.57 \pm 1.62$ & $109.02 \pm 6.33$ \\
\hline $\begin{array}{l}\text { BET Surface area } \\
\left(\mathrm{m}^{2} / \mathrm{g}\right)\end{array}$ & $418.3 \pm 17.7$ & $229.2 \pm 6.9$ \\
\hline
\end{tabular}

${ }^{a^{a}}$ The values are means \pm SD from triplicates $(n=3)$ of measurements for $\mathrm{pH}, 6$ replicates $(n=6)$ for CEC measured by $\mathrm{Ba}(\mathrm{OAc})_{2}$, triplicates $(n=3)$ for the $\mathrm{CEC}$ measured by $\mathrm{NH}_{4}-\mathrm{OAc}$, and 5 replicates $(n=5)$ for the BET surface area measured with $\mathrm{N}_{2}$ after a backfill with helium. 
soluble organic carbon that may be present in the biochar sample after the ozone treatment, the ozonized biochar sample was washed with $300 \mathrm{~mL}$ of Millipore water, and the $\mathrm{pH}$ for the washed ozonized biochar was measured to be $3.19 \pm 0.02$. Therefore, the bulk of the acidifying functional groups upon ozonization were associated with the biochar surface and only a small portion was associated with a soluble component.

Effect of Ozonization on Biochar CEC. Biochar cation exchange capacity (CEC) is a key property central to helping retain soil nutrients, reduce fertilizer runoff, and improve soil water retention. The present experimental study showed that the biochar ozonization can increase the biochar CEC value by a factor of 7-9 (nearly 10). The CEC value of untreated biochar (control) was determined to be $17.02 \pm 0.63 \mathrm{cmol} / \mathrm{kg}$ using the $\mathrm{AOAC} \mathrm{Ba}(\mathrm{OAc})_{2}$ method. Upon $90 \mathrm{~min}$ of dryozone treatment, the biochar CEC increased to $152.08 \pm 4.06$ $\mathrm{cmol} / \mathrm{kg}$ (Table 1), which to the best of our knowledge represents the highest biochar CEC value experimentally reached so far.

This is a significant result since the improvement of biochar CEC value by ozonization is now far much more than that of our previous study ${ }^{23}$ where we demonstrated the increase in the CEC value of biochars by a factor of 2 through ozonization of a pinewood-derived biochar produced by slow pyrolysis at $400{ }^{\circ} \mathrm{C}$ (P400).

The Biochar CEC was also independently measured by the USDA team using a somewhat different CEC assay method: the ammonium acetate (NH4OAc) method following adjustment to $\mathrm{pH}$ 7. The measurement with this method also confirmed the increase in CEC upon ozonization of the biochar. As measured with the modified ammonium acetate (NH4OAc) method, the CEC of the $90 \mathrm{~min}$ dry ozonized Rogue biochar (RBC 90D) was determined to be $109.09 \pm$ $6.33 \mathrm{cmol} / \mathrm{kg}$ while that of the untreated Rogue biochar control (RBC UN) was measured to be $14.57 \pm 1.62 \mathrm{cmol} / \mathrm{kg}$ (Table 1). The independent measurement conducted at the USDA laboratory confirmed the same trend in increasing the biochar CEC effected by the ozone treatment. The Rogue biochar is known to have a high surface area. In order to further understand the high increase in cation exchange capacity following ozonization, the surface area was measured on the Rogue Biochar in comparison with that of the P400 biochar.

BET Surface Area. The ground and sieved Rogue biochar samples before ozone treatment (RBC UN) had a surface area of $418.3 \mathrm{~m}^{2} / \mathrm{g}( \pm 17.7)$ as reported in Table 1 . Compared to the P400 with a measured surface area of only $2.05 \mathrm{~m}^{2} / \mathrm{g}$ $( \pm 0.42)$ as seen in Table S4, the Rogue biochar presents a very large surface area; Rogue biochar surface area is 200 times greater than P400 surface area. We believe that the high surface area of the Rogue biochar may make it more favorable to interact with ozone molecules. Therefore, the major difference on biochar CEC improvement between our present and previous studies ${ }^{23}$ may be attributed to the difference in BET surface area between the Rogue biochar and the P400.

Upon being ozonized, the ground and sieved Rogue biochar decreased in surface area to $229.2 \mathrm{~m}^{2} / \mathrm{g}( \pm 6.9)$ as seen in Table 1 . The drop in the measurable surface area upon being ozonized may be due to two factors: (1) It is possible that the ozone is causing the destruction of the pores of the biochar. (2) It is also possible that such a decrease in measurable surface area may be because of the oxygen-rich functional groups created in the micro/nanometer pores of the ozonized biochar that may in some extent obtrude the pores and/or coat the surface of the biochar. The method of BET surface area measurement uses nonpolar nitrogen gas as the adsorbate. Therefore, these nonpolar gases may be inadequate in terms of giving a true surface area when polar oxygen groups are obtruding the pores and/or coating the surface of the biochar.

In addition, in order to see the effect of grinding and sieving on the biochar, the surface area was also measured before and after ozonization from the unground biochar materials. The unground nonozonized biochar had a BET surface area of $377.4( \pm 22.2) \mathrm{m}^{2} / \mathrm{g}$ which is somewhat less than the ground nonozonized biochar control. After ozonization, the measured BET surface area of the unground biochar was 332.1 $( \pm 17.8)$ $\mathrm{m}^{2} / \mathrm{g}$ (Table S3). That is, the unground biochar samples also showed a slight drop in the measured surface area after ozonization. However, for the unground biochar samples, the drop in the surface area before and after ozonization is not as significant as it was observed for the ground biochar samples (Table 1). This may be due to the fact that the process of ozonization may have occurred more thoroughly on the ground biochar sample compared to the unground biochar sample.

FT-IR Analysis of Biochar. FT-IR technique was used for the identification and qualitative tracing of functional groups in biochar samples. Overall, FT-IR spectra showed a decrease in aromaticity and increase in carbonyl groups as a result of ozone treatment. Ozone treatment led to an increase in the relative intensity of a broad band centered at $3417 \mathrm{~cm}^{-1}$, which was assigned for the overlap of the $\mathrm{H}$-bonded $\mathrm{O}-\mathrm{H}$ stretching vibrations of hydroxyl groups from alcohols, phenols, and organic acids and $\mathrm{N}-\mathrm{H}$ stretching of amine. Bands at 2922 and $3026 \mathrm{~cm}^{-1}$ were assigned for alkyl and aromatic $\mathrm{C}-\mathrm{H}$ stretching, respectively, and the relative intensity of the alkyl band increased after the ozone treatment (Figure 2a). Bands at 1637 to $1616 \mathrm{~cm}^{-1}$ were assigned for aromatic and olefinic $\mathrm{C}=\mathrm{C}$ vibrations, $\mathrm{C}=\mathrm{O}$ in amide (I), ketone, and quinone groups, and the relative intensity of this band increased after the ozone treatment (Figure $2 \mathrm{~b}$ ), which could be due to the increase of the $\mathrm{C}=\mathrm{O}$ functional groups after ozone treatment. The bands at 1540 to $1560 \mathrm{~cm}^{-1}$ were assigned for $\mathrm{COO}^{-}$ asymmetric stretching, which are very weak in the RBC UN, and confirm that the extra carbonyl functional groups are added in the form of carboxylic acid. Two bands at 1494 and $1386 \mathrm{~cm}^{-1}$ were assigned for $\mathrm{N}-\mathrm{O}$ stretching. The band at $1451 \mathrm{~cm}^{-1}$ was assigned for alkyl $\mathrm{C}-\mathrm{H}$ bending. The relative intensities of several bands also decreased after the ozone treatment, including three bands at 1115,758 , and $471 \mathrm{~cm}^{-1}$ assigned for $\mathrm{Si}-\mathrm{O}$ stretching and bending. The band at 669 $\mathrm{cm}^{-1}$, which was only present in the RBC 90D, could be due to out of plane ring deformation (Figure $2 \mathrm{~b}$ ).

XPS Analysis of Biochar. The atomic concentration percentages on biochar surfaces measured by X-ray Photoelectron Spectroscopy (XPS) revealed that the ozone treatment caused a 2 -fold increase in the amount of oxygen present on the surface of the biochar (Table 2). The atomic percentages on the surface of the biochar were determined from the integrated intensity of the elemental photoemission features corrected by relative atomic sensitivity factors. The survey $\mathrm{C} 1 \mathrm{~s}$ and $\mathrm{O} 1 \mathrm{~s}$ spectra for the untreated control biochar and the ozonized biochar are shown in Figures S2 and S3. The ozone treatment caused an increase in total $\mathrm{O}$ concentration on the surface of the biochar from $13.93 \%$ to $23.70 \%$ (Table 

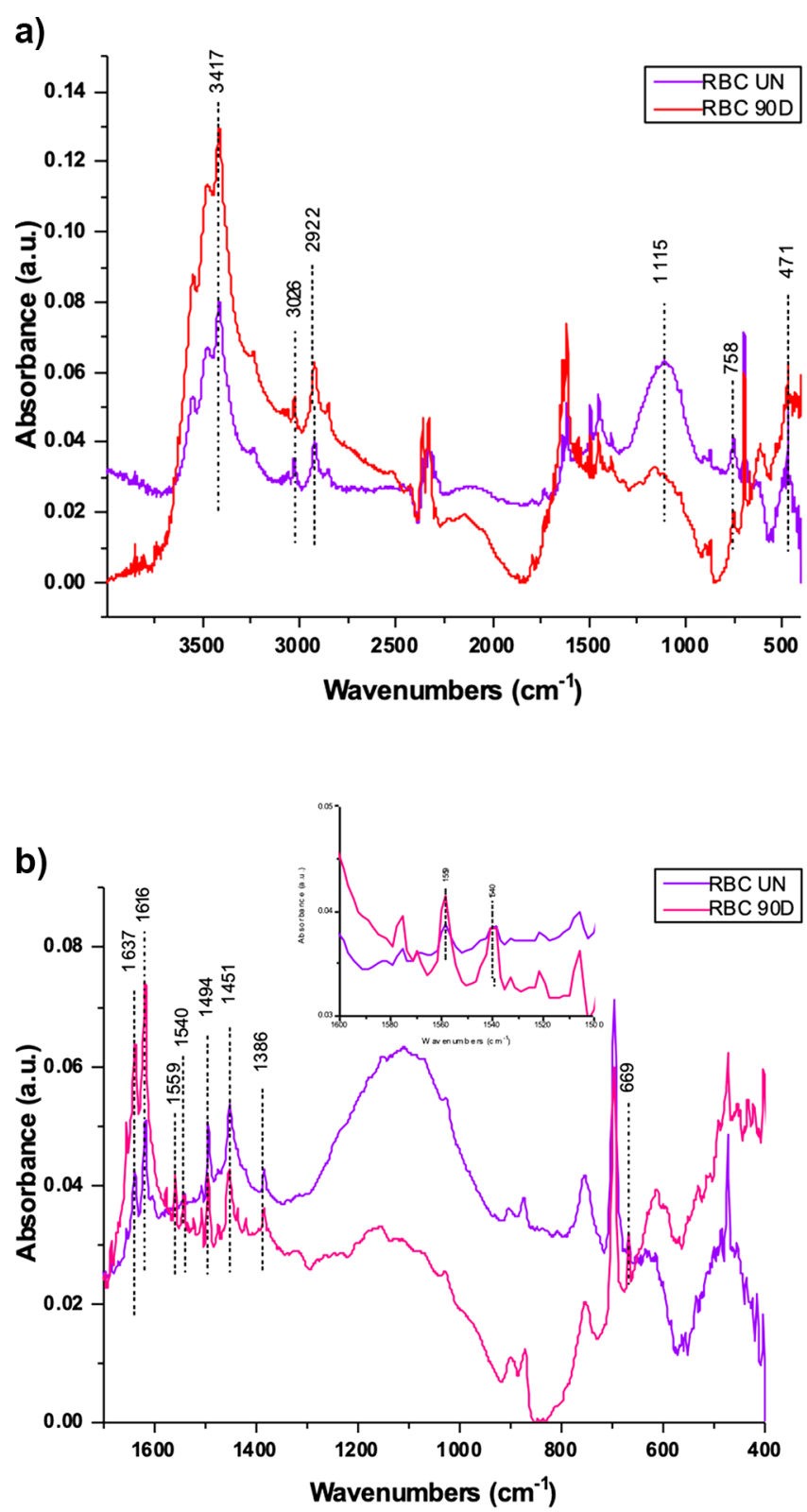

Figure 2. (a) FT-IR spectra from 400 to $4000 \mathrm{~cm}^{-1}$ for 90 min dry ozonized Rogue biochar (RBC 90D) and the untreated Rogue biochar (RBC UN) control. (b) FT-IR spectra from 400 to 1700 $\mathrm{cm}^{-1}$ for 90 min dry ozonized Rogue biochar (RBC 90D) and the untreated Rogue biochar (RBC UN) control along with an inset from 1500 to $1600 \mathrm{~cm}^{-1}$.
$2)$. The 2-fold increase in the amount of oxygen was mostly seen in the form of organic $\mathrm{C}=\mathrm{O}$ groups (e.g., carbonyl/ carboxyl) and $\mathrm{C}-\mathrm{O}$ (e.g., hydroxyl/ether) groups. The oxygen content in the form of $\mathrm{C}=\mathrm{O}$ went from $7.44 \%$ for the untreated control biochar to $11.57 \%$ for the ozonized biochar. This measurement confirmed our prediction in the installment of the oxygen groups mostly in the form of carboxyl groups. The carboxyl groups observed by XPS here also explain the drop in $\mathrm{pH}$ that was shown in Table 1 . The oxygen group installment post ozone treatment was also seen in the form of $\mathrm{C}-\mathrm{O}$; the untreated control biochar had a $\mathrm{C}-\mathrm{O}$ of $5.79 \%$, and it increased to $11.33 \%$ after ozone treatment (Table 2).

As a result, the formation of oxygen-functional groups including carboxylic acids on biochar surfaces have now, for the first time, been observed with XPS upon biochar surface oxygenation through the ozonization treatment. There is a strong correlation between the biochar oxygen-to-carbon ( $\mathrm{O} /$ $\mathrm{C})$ ratio and its $\mathrm{CEC}$, due to the negative charge on oxygen functional groups electrostatically attracting cations from solution. $^{28,29}$

The data in Table 2 showed that the molar $\mathrm{O} / \mathrm{C}$ ratio $(23.70 / 76.30=0.31: 1)$ on ozonized biochar surface is indeed significantly higher than that $(13.93 / 86.07=0.16: 1)$ of the control biochar surface. Therefore, biochar ozonization can indeed be used as a significant biochar surface oxygenation technique.

SEM Imaging and EDS Analysis of Ozonized Biochar. Scanning electron microscopy (SEM) imaging (Figure 3) showed that the biochar material had little difference before and after the ozonization treatment. This observation indicated that the ozonization process, indeed, did not visibly alter the biochar bulk material appearance as we predicted.

As shown in Figure 3, both biochar samples are fragments of honeycomb-like bulk biochar structure, with particle size $<100$ $\mu \mathrm{m}$. There is no noticeable difference in surface morphologies between the RBC UN and RBC 90D. The large variations of particle shape, size, and surface orientation can be used to explain the insignificant changes in $\mathrm{O} / \mathrm{C}$ ratios obtained by angle-resolved XPS as shown in Table S5 of the Supporting Information.

The Energy-Dispersive X-ray Spectroscopy (EDS) conducted during the SEM imaging showed that the mean $\mathrm{O} / \mathrm{C}$ ratio value of the ozonized biochar material $\mathrm{RBC} 90 \mathrm{D}$ was $0.16: 1$, which is slightly higher than that $(0.080: 1)$ of the control biochar (RBC UN) as listed in Table 3. The EDS result, which provides "bulk" elemental composition with information depth of $>1 \mu \mathrm{m}$, shows an increase of $\mathrm{O} / \mathrm{C}$ ratio of

Table 2. Representation of the Atomic Concentration (in \%) from XPS Measurement ${ }^{a}$

\begin{tabular}{|c|c|c|c|c|c|c|c|c|}
\hline \multicolumn{9}{|c|}{ Sample } \\
\hline Ozonized Biochar (RBC 90D) & $\mathrm{C}$ & & & & & $\mathbf{O}$ & & \\
\hline & 76.30 & & & & & 23.70 & & \\
\hline & $\mathbf{s p}^{2} \mathrm{C}$ & $\mathbf{s p}^{3} \mathrm{C}$ & $\mathrm{C}-\mathrm{O}$ & $\mathrm{C}=\mathrm{O}$ & $\mathrm{CO}_{3}$ & $\mathrm{C}=\mathrm{O}$ & $\mathrm{C}-\mathrm{O}$ & $\mathrm{H}_{2} \mathrm{O}$ \\
\hline & 29.00 & 21.56 & 11.72 & 11.06 & 2.96 & 11.57 & 11.33 & 0.80 \\
\hline \multirow[t]{4}{*}{ Control Biochar (RBC UN) } & $\mathrm{C}$ & & & & & o & & \\
\hline & 86.07 & & & & & 13.93 & & \\
\hline & $\mathbf{s p}^{2} \mathrm{C}$ & $\mathbf{s p}^{3} \mathrm{C}$ & $\mathrm{C}-\mathrm{O}$ & $\mathrm{C}=\mathrm{O}$ & $\mathrm{CO}_{3}$ & $\mathrm{C}=\mathrm{O}$ & $\mathrm{C}-\mathrm{O}$ & $\mathrm{H}_{2} \mathrm{O}$ \\
\hline & 38.80 & 27.75 & 8.98 & 6.32 & 4.22 & 7.44 & 5.79 & 0.70 \\
\hline
\end{tabular}

${ }^{a}$ The atomic percentages represented here were determined from the integrated intensity of the elemental photoemission features corrected by relative atomic sensitivity factors. The survey and C 1s/O 1s spectra are shown in Figures S2 and S3. The data represented here were measured by the Department of Chemistry in Virginia Tech. 

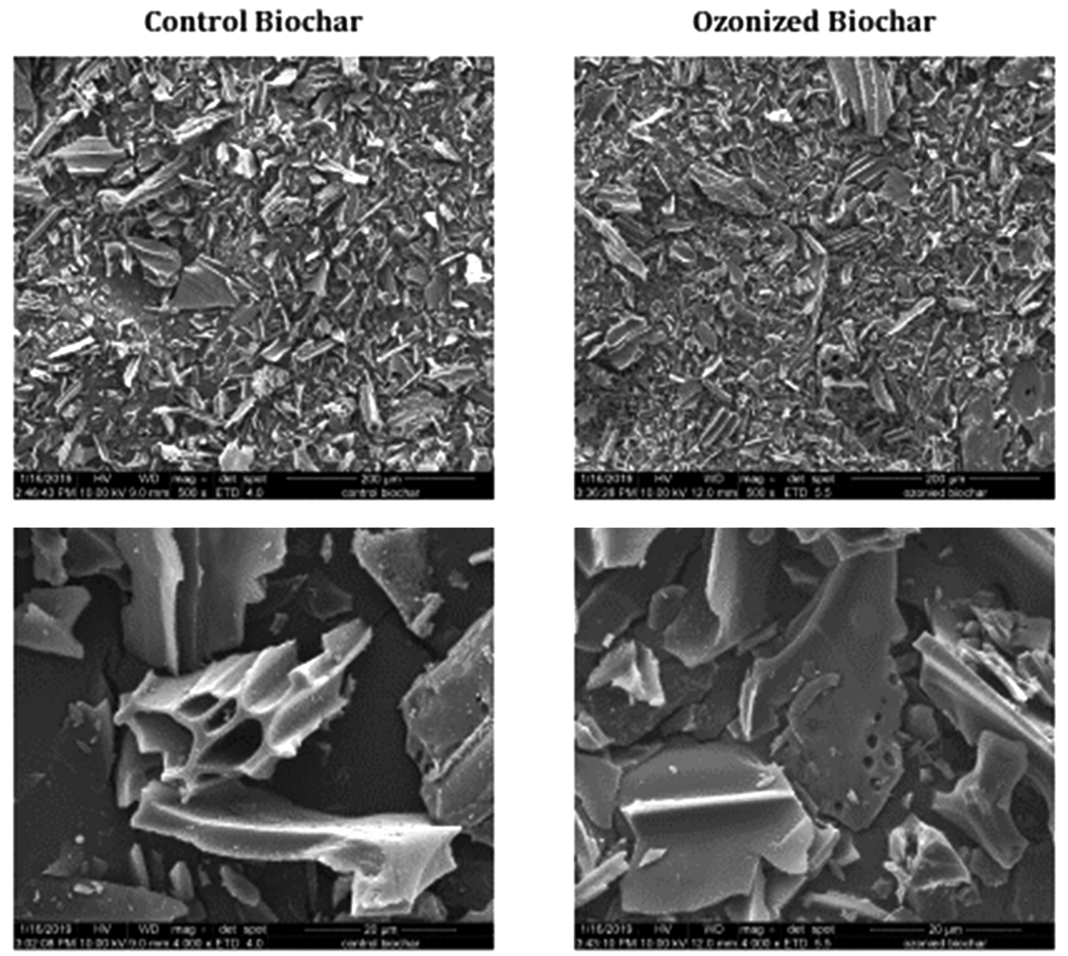

Figure 3. SEM images of the control biochar RBC UN (left) and ozonized biochar RBC 90D (right).

Table 3. SEM-EDS Analysis Result of Ozonized Biochar and Control Biochar ${ }^{a}$

\begin{tabular}{|c|c|c|c|}
\hline Sample & $\mathrm{C}$ & $\mathrm{O}$ & $\mathrm{O} / \mathrm{C}$ \\
\hline $\begin{array}{l}\text { Control biochar (RBC } \\
\text { UN) }\end{array}$ & $\begin{array}{l}92.26 \\
\quad( \pm 1.36)\end{array}$ & $7.74( \pm 1.36)$ & $\begin{array}{l}0.080 \\
( \pm 0.020)\end{array}$ \\
\hline $\begin{array}{l}\text { Ozonized biochar (RBC } \\
\text { 90D) }\end{array}$ & $\begin{array}{l}86.35 \\
( \pm 5.21)\end{array}$ & $\begin{array}{l}13.65 \\
( \pm 5.21)\end{array}$ & $0.16( \pm 0.07)$ \\
\hline
\end{tabular}

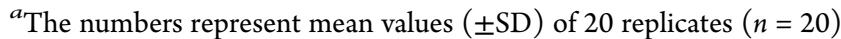
for the control biochar (RBC UN) and 20 replicates $(n=20)$ for the ozonized biochar (RBC 90D).

92.8\% (from 0.080 to 0.16 ) after ozone treatment. This value is about the same as the $94 \%$ increase (from 0.16 to 0.31 ) on the biochar particle surfaces obtained by XPS, which is quite surprising in regarding to the biochar surface oxygenation by ozonization where we expected the effect of ozonization to be noticeable only on the first molecular layer (likely within a few nanometers) of the biochar material surface.

When the specific biochar material RBC UN used in the study is considered, with such a high BET surface area (418.3 $\pm 17.7 \mathrm{~m}^{2} / \mathrm{g}$ ), it is so porous at the molecular scales that its averaged carbon material thickness between the porous spaces is only about $5 \mathrm{~nm}$. When such a thin $(5 \mathrm{~nm})$ piece of biochar carbon material is oxygenated at its two surface sides by ozone molecules, the resulting surface-oxygenated biochar carbon product may no longer be distinguishable by a comparison of the XPS and EDS measurements on $\mathrm{O} / \mathrm{C}$ ratio. For example, assuming the thickness of ozonization-enabled biochar surfaceoxygenation layer is about $1 \mathrm{~nm}$, it would result in a surfaceoxygenated biochar product with a structure of "oxygenated surface layer (1 $\mathrm{nm})$-biochar carbon layer (3 $\mathrm{nm})-$ oxygenated surface layer $(1 \mathrm{~nm})$ " that could no longer be distinguishable by the XPS and EDS measurements on the O/ $C$ ratio since the XPS measuring depth could be up to $10 \mathrm{~nm}$. Therefore, the XPS data (Table 2) and EDS data (Table 3) both showing a doubling of $\mathrm{O} / \mathrm{C}$ ratio in the $\mathrm{RBC} 90 \mathrm{D}$ sample are still consistent with the understanding that the ozonization process enables oxygenation at the first molecular layer (likely within a few nanometers) of the biochar material surface.

Dissolved Organic Carbon. Ozone treatment resulted in a low $\mathrm{pH}$ within its slurry as reported in Table 1 . We think that the process of ozonization results in the breakage of $\mathrm{C}=\mathrm{C}$ double bonds on the biochar material (Huff et al. 2018). ${ }^{23}$ Following that breakage, there should be organic carbon fragments of biochar with carboxylic groups "BiocharCOOH" (Huff et al. 2018). ${ }^{23}$ In order to further test the efficiency of ozone treatment on our biochar and to verify the formation of those "Biochar-COOH" fragments, the filtrate of the wash of the biochar was collected before and after ozonization for dissolved organic carbon concentration measurement. The effect of ozonization on the biochar was seen on the color of the filtrate extracted from the biochar. The filtrate from the nonozonized biochar appeared clear while the filtrate of the dry-ozonized biochar appeared dark brown thus indicating the presence of more organic carbon fragments (Figure S1). The total extracted DOC (dissolved organic carbon) from the dry-ozonized biochar was $10.98( \pm 1.00) \mathrm{mg}$ DOC/g biochar whereas the nonozonized biochar control only resulted in $2.10( \pm 0.23) \mathrm{mg} \mathrm{DOC} / \mathrm{g}$ biochar as reported in Table 4. Biochar ozonization leads to a high amount of dissolved organic carbon in its filtrate which is due to the oxygenation occurring on its surface leading to a breakage of the $\mathrm{C}=\mathrm{C}$ double bonds.

This result demonstrated that biochar ozonization can also produce certain amount of oxygenated biochar molecular fragments, which may be solubilized by liquid water as DOC for certain special applications such as the unlocking of phosphorus from insoluble phosphate materials in soils. ${ }^{30}$

Elemental (Oxygen and Carbon) Composition Analysis. In an attempt to characterize the elemental atomic 
Table 4. Amount of Dissolved Organic Carbon (DOC) Material Extracted from the Non-Ozonized Control Biochar and the Dry-Ozonized Biochar ${ }^{a}$

\begin{tabular}{lc}
\multicolumn{1}{c}{ Biochar Sample } & $\begin{array}{c}\text { DOC from Biochar }(\mathrm{mg} \mathrm{DOC} / \mathrm{g} \\
\text { biochar })\end{array}$ \\
$\begin{array}{l}\text { Nonozonized biochar control RBC } \\
\text { UN }\end{array}$ & $2.10( \pm 0.23)$ \\
$\begin{array}{l}\text { Dry-ozonized biochar RBC 90D } \\
{ }^{a} \text { The values are means } \pm \text { SD }(n=2) .\end{array}$ & $10.98( \pm 1.00)$ \\
\hline
\end{tabular}

content of the Rogue biochar before and after ozonization, elemental analysis was performed. Prior to ozonization, the biochar had a high content of carbon $(87.022 \mathrm{~mol} \% \pm 5.676)$ as reported in Table 5. Following ozonization, the carbon

Table 5. Elemental Analysis (Oxygen and Carbon) on the Non-Ozonized and Dry-Ozonized Rogue Biochar Samples ${ }^{a}$

$\begin{array}{llc} & \begin{array}{c}\text { Nonozonized Biochar } \\ (\text { RBC UN })\end{array} & \begin{array}{c}\text { Dry-ozonized Biochar } \\ (\text { RBC 90D })\end{array} \\ \begin{array}{c}\text { Oxygen mol \% } \\ ( \pm \text { SD })\end{array} & 6.669( \pm 1.301) & 13.926( \pm 1.590) \\ \begin{array}{c}\text { Carbon mol \% } \\ ( \pm \text { SD })\end{array} & 87.022( \pm 5.676) & 72.229( \pm 0.912) \\ \text { O/C mol ratio } & 0.077 & 0.193\end{array}$

${ }^{a_{T}}$ The values are moles average percentages from 6 replicates \pm SD. The weight percent of each element was converted to mole percent by using the respective molar mass of each element. The $\mathrm{O} / \mathrm{C}$ mol ratio was calculated from the averages of moles percentages of $\mathrm{O}$ and $\mathrm{C}$.

content dropped to $72.229 \mathrm{~mol} \%( \pm 0.912)$. In addition, following ozonization, there was a significant increase in oxygen content; the nonozonized control had $6.669 \mathrm{~mol} \%$ $( \pm 1.301)$ of oxygen whereas the ozonized sample had 13.926 mol \% $( \pm 1.590)$ of oxygen. The molar percentages of carbon and oxygen were used to calculate the molar $\mathrm{O} / \mathrm{C}$. The ozonization process increased the molar $\mathrm{O} / \mathrm{C}$ ratio by a factor of 2.5; the nonozonized control had a molar $\mathrm{O} / \mathrm{C}$ ratio of 0.077 whereas the dry-ozonized sample had a molar $\mathrm{O} / \mathrm{C}$ ratio of 0.193 (Table 5). Ozone treatment changed the molar percentages of oxygen and carbon in the Rogue biochar. Even though we did not expect the bulk properties of the biochar to be affected by ozone treatment, those results suggest that dryozone treatment may have altered the overall oxygen content of the biochar, as we observed with the SEM-EDS data (Table 3 ). To test the hypothesis that ozonization mostly happens on the surface of the biochar, we compared the changes in bulk properties before and after the ozonization of a high surface area biochar (Rogue Biochar) and a lower surface area biochar. Previously, in our lab, using P400 biochar, Huff et al. (2018) demonstrated that the bulk properties of the biochar did not vary as much following ozonization as we believed that the ozonization mechanism happened on the surface of biochar. In an attempt to explain this change in bulk properties, we measured the surface area of P400; we found that P400 biochar has a much smaller surface area (only $2.05 \pm 0.42 \mathrm{~m}^{2} /$ g) compared to the Rogue biochar $\left(389.9 \pm 10.3 \mathrm{~m}^{2} / \mathrm{g}\right)$ as measured using nitrogen as backfill following the evacuation procedure (Table S4). Therefore, we believe that the total oxygen groups installed on the surface of the Rogue biochar may be significant enough to slightly change the overall percentage of oxygen within the whole biochar sample, because of its exceptionally large BET surface area so that its averaged carbon material thickness between the porous spaces is only about $5 \mathrm{~nm}$. When such a $5 \mathrm{~nm}$ thin piece of biochar carbon material is oxygenated on its surfaces, the surface oxygenation may now become measurable even with bulk biochar elemental (O and $\mathrm{C}$ ) composition analysis. Therefore, the experimental results here are still consistent with the technology concept ${ }^{24}$ that ozonization mostly happens on the biochar surfaces.

Comparison of Surface Oxygenation Methods. The ozone treatment described here has promising advantages over previous work to enhance biochar CEC, particularly when applied to biochars with large surface areas. Prior approaches have included treatment with concentrated hydrogen peroxide, which resulted in a doubling of CEC (Huff and Lee, 2016); ${ }^{31}$ air oxidation of the biochar surface at $250{ }^{\circ} \mathrm{C}$ after pyrolysis also increased CEC by no more than a factor of 2 (Suliman et al., 2016); ${ }^{32}$ previous applications of ozone achieved a similar magnitude of CEC increase. For instance, Smith et al. $(2015)^{33}$ reported CEC increases of up to just about 20 and $7 \mathrm{cmol} \mathrm{kg}^{-1}$ for biochars produced from $500{ }^{\circ} \mathrm{C}$ pyrolysis of Douglas fir bark (DFBC) and Douglas fir wood (DFWC), respectively. Our previous study ${ }^{23}$ demonstrated the increase in CEC value of a pinewood-derived (P400) biochar through an ozone treatment from $15.39 \mathrm{cmol} \mathrm{kg}^{-1}( \pm 1.59)$ to $32.69 \mathrm{cmol} \mathrm{kg}^{-1}$ $( \pm 2.51)$, which is approximately $1 / 4$ th of the increase reported here. In addition to our effort in optimizing the biochar ozonization process, the major factor that contributed to the present success in producing such a super high cation exchange capacity biochar $(109-152 \mathrm{cmol} / \mathrm{kg})$ appeared to be the special characteristics of the Rogue Biochar with its BET surface area of about $400 \mathrm{~m}^{2} / \mathrm{g}$ (Table 1); whereas the P400 biochar used in our previous study ${ }^{23}$ had a BET surface area of only about $2.05( \pm 0.42) \mathrm{m}^{2} / \mathrm{g}$ (Table S4). The large surface area of the Rogue Biochar seems to be beneficial to its interaction with ozone molecules for surface oxygenation to achieve greater increase in biochar CEC value.

\section{CONCLUSION}

Through this experimental study, we have now demonstrated an improvement of biochar CEC value by a factor of nearly 10 through biochar surface oxygenation by ozonization. The CEC value of the untreated biochar was measured to be anywhere between 14 and $17 \mathrm{cmol} / \mathrm{kg}$. A $90 \mathrm{~min}$ dry ozonization treatment resulted in an increased biochar CEC value of 109$152 \mathrm{cmol} / \mathrm{kg}$, which is now almost comparable to that of certain humic materials such as humins. ${ }^{34-39}$ Simultaneously, the biochar ozonization process resulted in the reduction of biochar $\mathrm{pH}$ from 9.82 to as low as 3.07 , indicating the formation of oxygen-functional groups including carboxylic acids on biochar surfaces. Using the techniques of X-ray photoelectron spectroscopy, the formation of oxygen-functional groups including carboxylic acids on biochar surfaces have been observed upon biochar surface oxygenation through the ozonization treatment. The molar $\mathrm{O} / \mathrm{C}$ ratio $(23.70 / 76.30$ $=0.31: 1)$ on ozonized biochar surface as analyzed by XPS is indeed significantly higher than that $(13.93 / 86.07=0.16: 1)$ of the control biochar surface. Similarly, the elemental analysis data showed an increase in $\mathrm{O} / \mathrm{C}$ mol ratio from the control biochar (0.077) to the dry-ozonized biochar (0.193). The surface area measurements showed a decrease in BET surface area following ozone treatment with values of $418.3 \mathrm{~m}^{2} / \mathrm{g} \pm$ 17.7 (for the nonozonized control biochar) and $229.2 \mathrm{~m}^{2} / \mathrm{g} \pm$ 6.9 (for the dry-ozonized biochar). FTIR analysis also showed an increase in the content of oxygen-functional groups in the form of carbonyl groups on biochar surfaces upon ozonization, 
which can also produce a certain amount of oxygenated biochar molecular fragments that may be solubilized by liquid water for greater effects upon the application of biochar in soil.

\section{ASSOCIATED CONTENT}

\section{S Supporting Information}

The Supporting Information is available free of charge on the ACS Publications website at DOI: 10.1021/acssuschemeng.9b03536.

Characteristics of Rogue biochar, dissolved organic carbon, BET surface area, XPS angle resolved atomic concentration, SEM-EDS analysis, elemental analysis data of carbon and oxygen, picture of biochar filtrate and XPS spectra (PDF)

\section{AUTHOR INFORMATION}

\section{Corresponding Author}

*E-mail: jwlee@odu.edu. Phone: 757-683-4260.

ORCID $\odot$

Xu Feng: 0000-0003-1945-1605

John R. Morris: 0000-0001-9140-5211

Sandeep Kumar: 0000-0001-9707-7896

James W. Lee: 0000-0003-2525-5870

\section{Author Contributions}

G.K. performed the ozone treatment, FTIR measurement, $\mathrm{pH}$ measurement, certain CEC measurements, and wrote a portion of the manuscript. O.S. performed certain CEC measurements, the BET measurement, the DOC measurement, and wrote a portion of the manuscript. X.F. and J.R.M. conducted the XPS and EDS analyses on the biochar samples at Virginia Tech and wrote a part of the manuscript. C.P. and K.T. performed the independent CEC measurement on the biochar samples in their USDA lab and wrote a part of the manuscript. S.K. conducted the elemental analysis measurements. J.W.L. conceived the original concept of biochar surface oxygenation through ozonization, conducted this research project, and finalized the manuscript.

\section{Author Contributions}

${ }^{\$}$ G.K. and O.S. contributed equally to this article

\section{Notes}

The authors declare no competing financial interest.

\section{ACKNOWLEDGMENTS}

We thank Kameron Adams and Ashani Samaratunga for their assistance in BET, elemental analysis, and dissolved organic carbon concentration measurements, Thomas Wanzek for his technical support in biochar cation exchange capacity measurement at the USDA/ARS laboratory, and the summer students of the REU projects (NSF Award number: 1560194 and CHE-1659476) at ODU for their participation in technical support for this research. We thank our summer REU undergraduate students Jorge Morales, Ryan Gunter, and James Dawe for their help in preparing some of the biochar materials. We thank Drs. Jim Ippolito and Kurt Spokas for their stimulating discussions on biochar research and Mr. Grant Scheve of Oregon Biochar Solutions for generously sending the Rogue biochar samples and associated biochar characterization data used in this study. This research was supported, in part, by the Old Dominion University Multidisciplinary Seed Funding Program and by Dr. Lee's start-up research funds provided by the Department of Chemistry and Biochemistry, the College of
Sciences, the Office of Research at ODU, and the ODU Research Foundation. XPS analysis at Virginia Tech was supported by the National Science Foundation under Grant No. CHE-1531834.

\section{REFERENCES}

(1) Biederman, L. A.; Harpole, W. S. Biochar and its effects on plant productivity and nutrient cycling: a meta-analysis. GCB Bioenergy 2013, 5, 202-214.

(2) Jeffery, S.; Verheijen, F. G. A.; van der Velde, M.; Bastos, A. C. A quantitative review of the effects of biochar application to soils on crop productivity using meta-analysis. Agric., Ecosyst. Environ. 2011, 144, 175-187.

(3) Spokas, K. A.; et al. Biochar: A Synthesis of Its Agronomic Impact beyond Carbon Sequestration. J. Environ. Qual 2012, 41, 973-989.

(4) Glaser, B.; Lehmann, J.; Zech, W. Ameliorating physical and chemical properties of highly weathered soils in the tropics with charcoal - a review. Biol. Fertil. Soils 2002, 35, 219-230.

(5) Liang, B.; et al. Black Carbon Increases Cation Exchange Capacity in Soils. Soil Sci. Soc. Am. J. 2006, 70, 1719-1730.

(6) Xu, R. K.; Zhao, A. Z.; Yuan, J. H.; Jiang, J. pH buffering capacity of acid soils from tropical and subtropical regions of China as influenced by incorporation of crop straw biochars. J. Soils Sediments 2012, 12, 494-502.

(7) Laird, D. A.; et al. Impact of biochar amendments on the quality of a typical Midwestern agricultural soil. Geoderma 2010, 158, 443449.

(8) Ramos, F. T.; et al. Soil organic matter doubles the cation exchange capacity of tropical soil under no-till farming in Brazil. J. Sci. Food Agric. 2018, 98, 3595-3602.

(9) Pignatello, J. J., Uchimiya, M., Abiven, S., Schmidt, M. W. I.. Evolution of biochar properties in soil. In Biochar for Environmental Management: Science, Technology and Implementation;Lehmann, J., Joseph, S., Eds.; Routledge: Sterling, VA, 2015; pp 195-233.

(10) Kavitha, B.; et al. Benefits and limitations of biochar amendment in agricultural soils: A review. J. Environ. Manage. 2018, $227,146-154$.

(11) Katterer, T.; et al. Biochar addition persistently increased soil fertility and yields in maize-soybean rotations over 10 years in subhumid regions of Kenya. Field Crop Res. 2019, 235, 18-26.

(12) El-Naggar, A.; et al. Biochar application to low fertility soils: A review of current status, and future prospects. Geoderma 2019, 337, $536-554$.

(13) Hailegnaw, N. S.; Mercl, F.; Pracke, K.; Szakova, J.; Tlustos, P. Mutual relationships of biochar and soil $\mathrm{pH}, \mathrm{CEC}$, and exchangeable base cations in a model laboratory experiment. J. Soils Sediments 2019, $19,2405-2416$.

(14) Igaz, D.; et al. Can a single dose of biochar affect selected soil physical and chemical characteristics? Vodohospod. Cas. 2018, 66, $421-428$.

(15) Mensah, A. K.; Frimpong, K. A. Biochar and/or Compost Applications Improve Soil Properties, Growth, and Yield of Maize Grown in Acidic Rainforest and Coastal Savannah Soils in Ghana. Int. J. Agron. 2018, 2018, 1.

(16) Ding, Y.; et al. Potential Benefits of Biochar in Agricultural Soils: A Review. Pedosphere 2017, 27, 645-661.

(17) Lee, J. W.; et al. Characterization of biochars produced from peanut hulls and pine wood with different pyrolysis conditions. Bioresources and Bioprocessing 2016, 3, 15.

(18) Lee, J. W.; Hawkins, B.; Day, D. M.; Reicosky, D. C. Sustainability: the capacity of smokeless biomass pyrolysis for energy production, global carbon capture and sequestration. Energy Environ. Sci. 2010, 3, 1695-1705.

(19) Liu, X.; Mao, P. N.; Li, L. H.; Ma, J. Impact of biochar application on yield-scaled greenhouse gas intensity: A meta-analysis. Sci. Total Environ. 2019, 656, 969-976. 
(20) Aller, D. M.; et al. Long term biochar effects on corn yield, soil quality and profitability in the US Midwest. Field Crop Res. 2018, 227, $30-40$.

(21) Lee, J. W.; et al. Characterization of Biochars Produced from Cornstovers for Soil Amendment. Environ. Sci. Technol. 2010, 44, 7970-7974.

(22) Spokas, K. A. Review of the stability of biochar in soils: predictability of O: C molar ratios. Carbon Manage. 2010, 1, 289303.

(23) Huff, M. D.; Marshall, S.; Saeed, H. A.; Lee, J. W. Surface oxygenation of biochar through ozonization for dramatically enhancing cation exchange capacity. Bioresources and Bioprocessing 2018, 5, 18.

(24) Lee, J. W. Ozonized Biochar Compositions And Methods Of Making And Using The Same. United States Patent No. US 10,971,335 B2 (2018).

(25) Rippy, J. F. M.; Nelson, P. V. Cation exchange capacity and base saturation variation among Alberta, Canada, moss peats. HortScience 2007, 42, 349-352.

(26) Munera-Echeverri, J. L.; et al. Cation exchange capacity of biochar: An urgent method modification. Sci. Total Environ. 2018, 642, 190-197.

(27) Valdes, H.; Sanchez-Polo, M.; Rivera-Utrilla, J.; Zaror, C. A. Effect of ozone treatment on surface properties of activated carbon. Langmuir 2002, 18, 2111-2116.

(28) Huff, M. D.; Kumar, S.; Lee, J. W. Comparative analysis of pinewood, peanut shell, and bamboo biomass derived biochars produced via hydrothermal conversion and pyrolysis. J. Environ. Manage. 2014, 146, 303-308.

(29) Lee, J. W.; et al. Characterization of Biochars Produced from Cornstovers for Soil Amendment. Environ. Sci. Technol. 2010, 44, 7970-7974.

(30) Lee, J. W. Ozonized biochar: phosphorus sustainability and sand soilization. Patent Application pending (2018).

(31) Huff, M. D.; Lee, J. W. Biochar-surface oxygenation with hydrogen peroxide. J. Environ. Manage. 2016, 165, 17-21.

(32) Suliman, W.; et al. Modification of biochar surface by air oxidation: Role of pyrolysis temperature. Biomass Bioenergy 2016, 85, $1-11$.

(33) Smith, M.; Ha, S.; Amonette, J. E.; Dallmeyer, I.; Garcia-Perez, $M$. Enhancing cation exchange capacity of chars through ozonation. Biomass Bioenergy 2015, 81, 304-314.

(34) Kyziol, J.; Twardowska, I.; Schmitt-Kopplin, P. The role of humic substances in chromium sorption onto natural organic matter (peat). Chemosphere 2006, 63, 1974-1982.

(35) Harada, Y.; Inoko, A. Cation-exchange properties of soil organic matter. Soil Sci. Plant Nutr. 1975, 21, 361-369.

(36) Kelessidis, V. C.; Papanicolaou, C.; Foscolos, A. Application of Greek lignite as an additive for controlling rheological and filtration properties of water-bentonite suspensions at high temperatures: A review. Int. J. Coal Geol. 2009, 77, 394-400.

(37) Lofgren, S.; Cory, N.; Zetterberg, T.; Larsson, P. E.; Kronnas, $\mathrm{V}$. The long-term effects of catchment liming and reduced sulphur deposition on forest soils and runoff chemistry in southwest Sweden. For. Ecol. Manage. 2009, 258, 567-578.

(38) Kelessidis, V. C.; et al. Greek lignites as additives for controlling filtration properties of water-bentonite suspensions at high temperatures. Fuel 2007, 86, 1112-1121.

(39) Seyedbagheri, M. M. Influence of Humic Products on Soil Health and Potato Production. Potato Res. 2010, 53, 341-349. 